\title{
Behaviour of Low cost Tiles and Bricks Manufactured using Agricultural Wastes
}

\author{
Jagan Sivamani
}

\begin{abstract}
In this study, an attempt has been taken to utilize the wastes produced from agriculture as a partial replacement to scarce material like fine aggregate in the manufacturing of useful construction materials. Also, Waste Sludge (WS) generated through treatment plant from Kalasalingam Academy of Research and Education was used suitably as one of the ingredients in the manufacturing of construction materials. Various other wastes generated through agriculture such as Banana Fiber (BF), Rice Husk Ash (RHA), and Sugarcane Bagasse Ash (SBA) was also utilized suitably after pre-treatment in the manufacture of tiles and bricks. Five different mixes under various levels of replacement of waste sludge and agricultural wastes were prepared to study its behavioral performance. Various tests conducted to study the performance behavior include Compressive Strength, Water Absorption and Physical Parametric tests on both brick and tile specimens. Results indicate that all physical and mechanical properties of bricks and tiles fall within BIS standards by the combination with a higher percentage of Red Soil,Sugarcane fiber and Waste Sludge.
\end{abstract}

Keywords:Agricultural wastes, Bricks, Fine Aggregate, Pre-treatment, Tiles and Waste Sludge

\section{INTRODUCTION}

Industrialization is one of the important emergent from urbanization that has created greater impact over the scarcity in the construction materials [1]. Also, it had to lead to the over consumption of natural resources that had depleted it as well. So this had necessitated the utilization of alternative waste materials that achieved the sustainability in environment. Initially field surveys carried out at the surrounding villages nearby Krishnankoil indicate the large amount of wastes was being produced through BF, RHA and SBA. Later quantity of WS produced from the treatment plant at Kalasalingam Academy of Research and Education were subjected to initial treatments and dried and powdered suitably to be used as an alternative material to fine aggregate. BF and RHA were collected from the village near Melur, Madurai and SBA was collected from the sugarcane industry located at thoothukudi. Various alternative material combinations under different levels of replacement yielded better results in the manufacture of bricks. Usage of alternative waste materials like SBA in combination with Quarry Dust (QD) and Lime yielded double the compressive strength compared to conventional clay bricks [2]. Apart from wastes generated through agriculture, WS from treatment plants was dried and used as ingredient in the manufacture of bricks. From the previous studies conducted

Revised Manuscript Received on December 30, 2019.

*Jagan Sivamani

Jagan Sivamani*, Department of Civil Engineering, Kalasalingam Academy of Research and Education, Krishnankoil, India. Email: s.jagan@klu.ac.in by [3], the maximum percentage of addition of dried sludge was limited to $10 \%$, as beyond it decreases the compressive strength compared to clay bricks which was too evident from the study conducted by [4]. Now day's researchers are focusing on use of waste materials in improving the strength and durability of characteristic materials [5]. Usage of RHA as an additive material for the manufacture of bricks resulted in compressive strength at even smaller percentages [6], but addition beyond the limitation reduced its durability characteristics as it absorbs more water due to its increased surface area [7].Similar to studies on RHA, even SBA shows the same phenomenon of deprived durability characteristics [8]. Roof tiles manufactured with waste materials like RHA and SBA indicate that combination with $25 \%$ of water absorption as the optimum level of addition of chemical activators [9]. On other hand BF along with RHA also indicate that combination with $25 \%$ of water absorption as the optimum level of addition of chemical activators [10]. From the above two studies, it could be found that experimentation was done by replacing SBA with BF. No such variations were performed with RHA as it helps in enhancing the early age mechanical properties as well long term strength properties of concrete tiles [11]. In this research drive, waste materials such as Banana Fiber (BF), Rice Husk Ash (RHA), Sugarcane Bagasse Ash (SBA) and Waste Sludge (WS) have been used for the manufacture of bricks and tiles under five different levels of replacement by varying the percentage of ingredients. Use of such pre-treated waste materials not only improves the performance of construction materials but also prominent in achieving the sustainability towards the environment.

\section{RESEARCH SIGNIFICANCE}

Due to urbanization encompassed with industrialization, researchers have been involuntary in finding an alternative material to be utilized in the field of construction as a result of excessive depletion of natural resources. This initiative had been taken keeping into consideration on excessive utilization of fine aggregate and clay materials. Also on other hand, it was found that large amount of agricultural wastes and sludge produced being dumped in the open environment leading to disposal problems. With the focus on societal concern, finding the solution to above two problems lead to the utilization of waste sludge and agricultural wastes in the manufacturing of bricks and tiles. Waste Sludge and agricultural wastes are subjected to pre-treatment before its utilization in manufacturingprocess. 


\section{Behaviour of Low cost Tiles and Bricks Manufactured using Agricultural Wastes}

\section{MATERIALS AND METHODOLOGY}

\section{A. Raw Materials}

Red Soil (RS), pre-treated waste materials like Rice Husk Ash (RHA), Sugarcane Bagasse Ash (SBA), Banana Fiber (BF) and Waste Sludge (WS) and chemical activators like Sodium hydroxide in combination with Sodium silicate solution were used as raw materials for the manufacturing of bricks and tiles. RS was collected from the locally available site near Krishnankoil. RHA was collected from Ucharichanpatti village near to Melur, Madurai. SBA was collected from the sugarcane industry located at thoothukudi and BF was collected from Thaniyamangalan village, Sivagangai. WS was collected from the treatment plant located at Kalasalingam Academy of Research and Education, Krishnankoil. Bricks and tiles specimens were prepared manually using standard wooden moulds at the site.

\section{B. Pre-treatment methods}

All the raw materials collected locally and from industries were subjected to pre-treatments for its suitability in use of manufacturing of bricks and tiles. Initially, WS collected in theform of semi-solid from Kalasalingam Academy of Researchand Education subjected to slow sand filtration technique toseparate the solid content, dried in open environment andgrounded for its use in the powdered form as shown in the fig. 1. SBA as collected from the site is found to have lots of impurities,soapre-treatmenttechniqueofgrindingandsieving was adopted [12]. Similarly RHA and BF was pre-treated in the similar manner of SBA. All the pre-treated raw materials were shown in the fig. 2 .

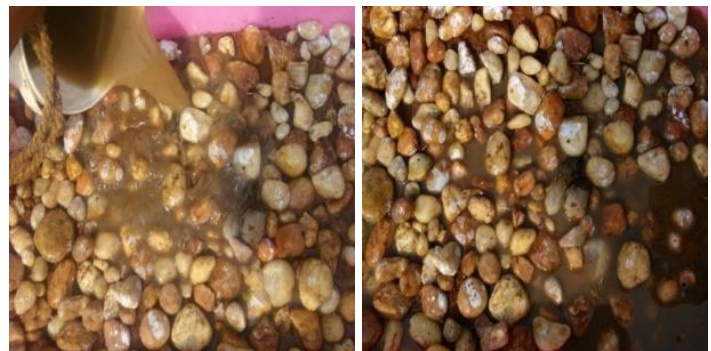

Fig.1.Purification of Waste Sludge
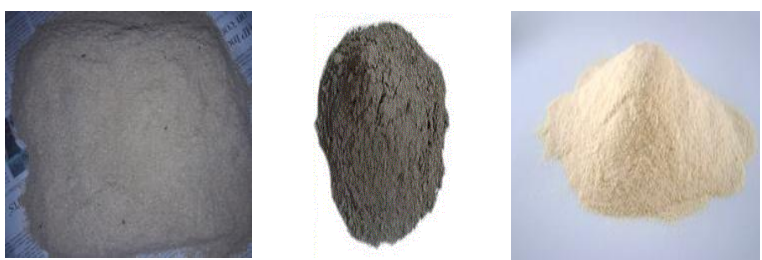

Fig.2.Pre-treated RHA, SBA and BF

\section{Preparation of test specimens}

Standard wooden moulds of size $200 \mathrm{~mm} \times 200 \mathrm{~mm} \times 25 \mathrm{~mm}$ for tiles and 190mmx90mmx90mm for bricks were pre-fabricated for the manufacturing of bricks and tiles. All the brick and tiles specimens were prepared as per the mix specified in the table I. Proportions of materials were mixed with suitable quantity of water and chemical activators of
9M. Prepared mix was then allowed to dry 2 to 3 hours to achieve homogeneity in mixture. Tile and brick moulds were then filled with the prepared mix in three layers tamped under steel rod for 25 times, which was then levelled using trowel. Specimens were then dried for about 10 days and placed in kiln for about 45 days which was then burnt at $800^{\circ} \mathrm{Cf}$ or 36 hours.Preparedtilesandbrickspecimenswerepresented in the figure 3 (a) and $3(\mathrm{~b})$.

\section{Table- I: Mix Proportion of Raw Materials}

\begin{tabular}{|c|c|c|c|c|c|c|c|c|}
\hline \multirow[t]{2}{*}{ No } & \multirow[t]{2}{*}{ Mix } & \multicolumn{3}{|c|}{ Bricks (B) } & \multicolumn{4}{|c|}{$\begin{array}{l}\text { Tiles } \\
\text { (T) }\end{array}$} \\
\hline & & $W S$ & $S B A$ & RHA & $R S$ & $B F$ & $R H A$ & $S B A$ \\
\hline 1 & R0 & $0 \%$ & $0 \%$ & $0 \%$ & $0 \%$ & $0 \%$ & $0 \%$ & $0 \%$ \\
\hline 2 & R1 & $\begin{array}{l}60 \\
\% \\
\end{array}$ & $30 \%$ & $10 \%$ & $50 \%$ & $30 \%$ & $\begin{array}{l}10 \\
\%\end{array}$ & $10 \%$ \\
\hline 3 & $\mathrm{R} 2$ & $\begin{array}{l}55 \\
\% \\
\end{array}$ & $35 \%$ & $10 \%$ & $45 \%$ & $35 \%$ & $\begin{array}{l}10 \\
\%\end{array}$ & $10 \%$ \\
\hline 4 & R3 & $\begin{array}{l}50 \\
\% \\
\end{array}$ & $30 \%$ & $20 \%$ & $45 \%$ & $25 \%$ & $\begin{array}{l}15 \\
\%\end{array}$ & $15 \%$ \\
\hline 5 & $\mathrm{R} 4$ & $\begin{array}{l}40 \\
\%\end{array}$ & $30 \%$ & $30 \%$ & $40 \%$ & $20 \%$ & $\begin{array}{l}20 \\
\%\end{array}$ & $20 \%$ \\
\hline 6 & $\overline{\mathrm{R} 5}$ & $\begin{array}{l}70 \\
\%\end{array}$ & $20 \%$ & $10 \%$ & $50 \%$ & $20 \%$ & $\begin{array}{l}10 \\
\%\end{array}$ & $20 \%$ \\
\hline
\end{tabular}

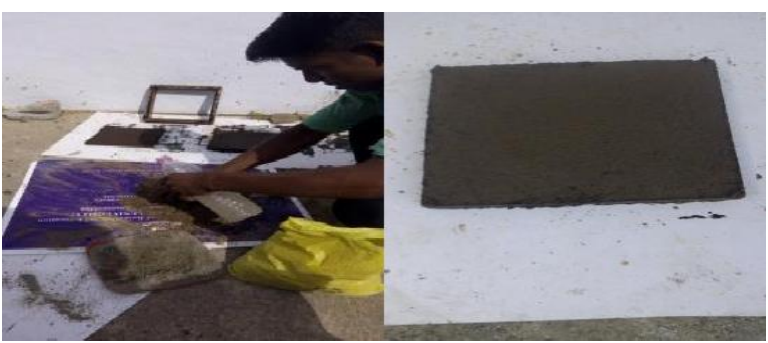

Fig.3a.Casting of tile specimens

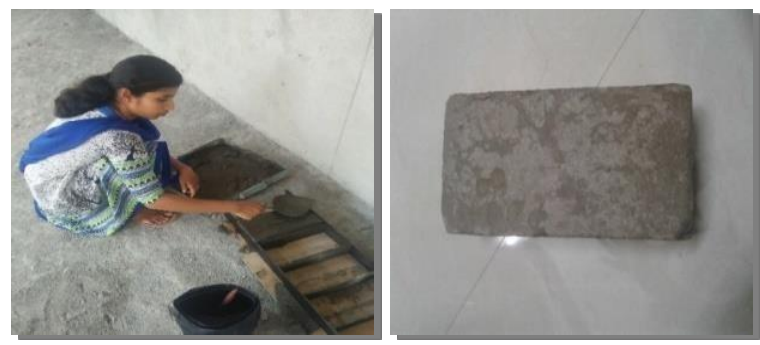

Fig.3b. Casting of brick specimens

\section{Testing of specimens}

To study the performance behaviour of casted specimens compressive strength test, water absorption test were conducted under all levels of replacement. Also other physical parametric tests were size and shape, colour, abrasion and soundness tests were also performed in comparison with standard clay bricks. In case of bricks, compressive strength test were performed on $24 \mathrm{~h}$ oven dried bricks. Specimens were subjected to a loading rate of $1.25 \mathrm{~mm} / \mathrm{min}$. In case of tiles, tiles were initially placed over an elevated support on its four corners, and then the bricks and concrete cubes of known weight were placed over the tiles. Maximum load at which the tile specimens fail were determined and calculated as its compressive strength. Water absorption of brick and tile specimens were done in accordance with ASTM C67, wherein the specimens with initial weight noted down were immersed in clean water for $24 \mathrm{~h}$. Afterwards, specimens were taken

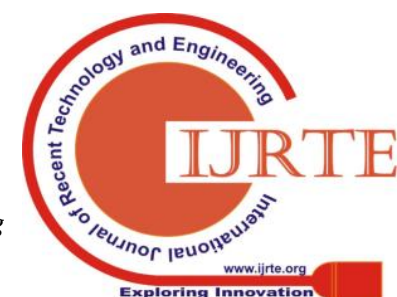


out and wiped off and its final weight was determined. Test set up to determine the compressive strength of tiles is presented in the fig. 4 .

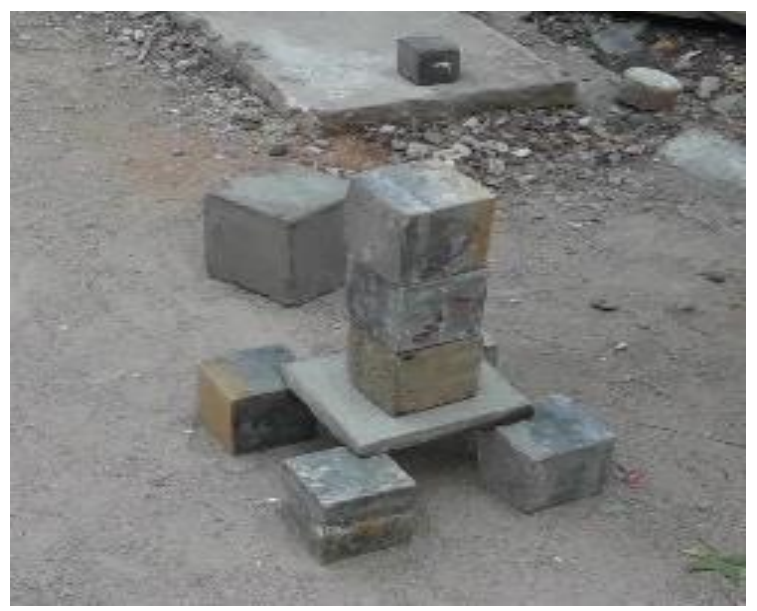

Fig.4.Test set up

\section{RESULTS AND DISCUSSIONS}

\section{A. Specific Gravity}

Specific gravity for all levels of replacement for both tile and brick specimens are presented in the table II. Specific gravity of Clay bricks is found to be 2.24 and for tiles it is found to be 2.76. It was observed that the Specific gravity of all levels of replacements is lesser compared to that of clay bricks which is mainly due to the lesser specific gravity of raw waste materials used. This concludes that lighter bricks and tiles can be manufactured using agricultural waste and waste sludge.

Table- II: Specific Gravity

\begin{tabular}{|c|c|c|c|}
\hline S. No & Mix & Bricks (B) & Tiles (T) \\
\hline 1 & R0 & 2.24 & 2.76 \\
\hline 2 & R1 & 1.69 & 2.47 \\
\hline 3 & R2 & 1.78 & 2.45 \\
\hline 4 & R3 & 1.80 & 2.47 \\
\hline 5 & R4 & 1.91 & 2.48 \\
\hline 6 & R5 & 1.51 & 2.53 \\
\hline
\end{tabular}

\section{B. Compressive strength}

Compressive strength at the age of 28 days for both tile and brick specimens are presented in the table III. From the results, the maximum compressive strength was observed for R3 (B) and R4 (T) which is nearly on an average of $30 \%$ higher than the conventional specimens. In case of bricks, compressive strength of $\mathrm{R} 1(\mathrm{~B})$ is $5.4 \%$ more compared to $\mathrm{R} 0(\mathrm{~B})$; $\mathrm{R} 2(\mathrm{~B})$ is $23 \%$ more compared to R0(B); R3(B) is 34\% more compared to R0(B); R4(B) is 39\% more compared to $\mathrm{R} 0(\mathrm{~B})$; R5(B) is 30\% more compared to R0(B). Such maximum increase in compressive strength observed under R3 combination is mainly due to increase in percentage of BF and WS. Also decrease in percentage of RHA and SBA had greater contribution towards the increase in the compressive strength which was also observed in case of tiles. This is because of increased fineness of RHA which has the ability to absorb more water thereby reducing the strength of bricks and tiles.

Table- III: Compressive strength at 28 days

\begin{tabular}{|c|c|c|c|}
\hline \multirow[t]{2}{*}{ S. No } & \multirow[t]{2}{*}{ Mix } & \multicolumn{2}{|c|}{ Compressive Strength $\left(\mathrm{N} / \mathrm{mm}^{2}\right)$} \\
\hline & & $\begin{array}{c}\text { Bricks } \\
\text { (B) }\end{array}$ & $\begin{array}{l}\text { Tiles } \\
\text { (T) }\end{array}$ \\
\hline 1 & R0 & 3.50 & 8.70 \\
\hline 2 & R1 & 3.73 & 11.34 \\
\hline 3 & $\mathrm{R} 2$ & 4.60 & 11.21 \\
\hline 4 & R3 & 5.30 & 9.43 \\
\hline 5 & $\mathrm{R} 4$ & 5.7 & 8.91 \\
\hline 6 & R5 & 3.61 & 10.36 \\
\hline
\end{tabular}

\section{Water Absorption}

Compressive strength at the age of 28 days for both tile and brick specimens are presented in the table IV. From the test values, it could be observed that maximum reduction in water absorption is observed in case of mix R4 (B) and R4 (T) where the percentage of RHA is very minimal. This satisfies the condition for optimal usage of RHA in manufacturing of concrete as well as other construction materials [13]. Such increased water absorption characteristics of mix with RHA is due to the higher fineness of RHA. Such finer RHA absorbs more water which in turns reduces the performance of both bricks and tiles. On the other hand, the decrease in the percentage of water absorption could be evident in the mix R2 (B) and R2(T).

Table- IV: Water Absorption at 28 days

\begin{tabular}{|c|c|c|c|}
\hline \multirow{2}{*}{ S. No } & \multirow{2}{*}{ Mix } & \multicolumn{2}{|c|}{ Water Absorption (\%) } \\
\cline { 3 - 4 } & & $\begin{array}{c}\text { Bricks } \\
\text { (B) }\end{array}$ & Tiles (T) \\
\hline 1 & R0 & 22 & 9.70 \\
\hline 2 & R1 & 21.43 & 9.43 \\
\hline 3 & R2 & 20.12 & 8.76 \\
\hline 4 & R3 & 18.67 & 10.23 \\
\hline 5 & R4 & 31.42 & 11.42 \\
\hline 6 & R5 & 26.39 & 10.79 \\
\hline
\end{tabular}

\section{Physical Parametric tests}

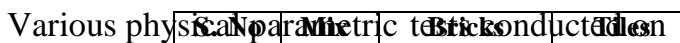 the manufactured brieks and tiles as presented in the fig.5.} Bricks and tiles manufactured using agricultural wastes is grey in colour. This grey colored of the bricks and tiles is mainly due to the addition of ingredients during the manufacturing process. Bricks satisfied the impact test as it does not crack when dropped at a height of $1 \mathrm{~m}$. Also it produced a metallic ringing sound when it been struck with each other. Also, the bricks manufactured were rectangular in shape with sharp edges of standard size 190mmx190mmx90mm. All these standard physical parametric tests satisfy the BIS standards of bricks that are to be used in the field [14]. All the tiles manufactured were rectangular in shape with sharp edges of standard size $200 \mathrm{~mm} \times 200 \mathrm{~mm} \times 20 \mathrm{~mm}$ [15]. 


\section{Behaviour of Low cost Tiles and Bricks Manufactured using Agricultural Wastes}
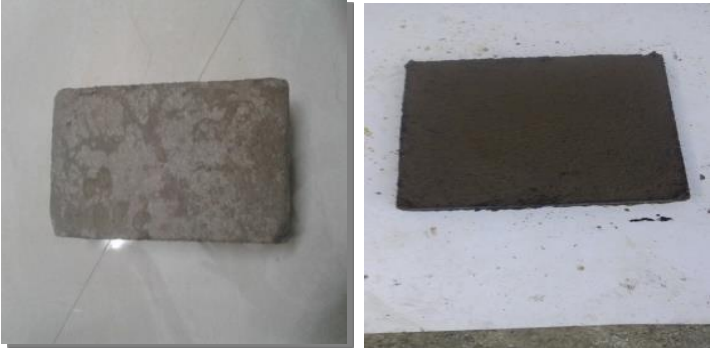

Fig.5.Manufactured brick and tile specimens

\section{CONCLUSION}

In this study, behaviour of bricks and tiles by the addition of Waste Sludge from treatment plant and agricultural wastes like Rice Husk Ash (RHA), Banana Fibre (BF), and Sugarcane Bagasse Ash (SBA) as ingredient can be considered as an ideal way for recycling and safe disposal of agricultural wastes and sludge. All these agricultural wastes are being collected at free of cost from the farmers in nearby villages, having higher percentage of silica in it and suitably can also act as a filler material. Maximum strength of bricks and tiles compared to conventional clay materials were achieved under R4 (B) and R2 (T), which is 39\% and $34 \%$ more compared to conventional specimens, wherein the percentages of waste sludge and Red soil are high. This attributes towards the increase in the compressive strength. With respect to its durable behaviour, maximum percentage of water absorption is achieved under R4 (B) and R4 (T), wherein the percentages of RHA and SBA are high. As we know in practice these two are finer materials having higher surface area, which contributes to the increase in the water absorption. It could also be observed that all thewaste ingredients are added at percentages that falls under the limits of usage as conducted by previous researchers in their study. Finally it could be concluded that usage of finer waste materials such as Sugarcane Bagasse Ash and Rice Husk Ash at lesser ratios and Banana Fibers, Waste Sludge and Red Soil at higher ratios will result in effective production of bricks and tiles and efficient disposal of wastes leading to economical and sustainable environment.

\section{REFERENCES}

1. Pappu Asokan, Saxena Mohini, Asolekar Shyam R, "Solid wastes generation in India and their recycling potential in building materials" Build Environment, vol. 42, Aug. 2007, pp. 2311-2320.

2. Mangesh V. Madurwar, Rahul V, Ralegaonkar, Sachin A and Mandavgane, "Application of agro-waste for sustainable construction materials: A review" Construction and Building Materials., vol. 38, April. 2017, pp. 872-878.

3. Joo-Hwa Tay, "Bricks Manufactured from Sludge" Journal of Environmental Engineering, vol. 113, October. 1987, pp. 278-284.

4. Ritu Daheriya and V V Singh, "An experimental investigation of the use of industrial waste and sewage sludge for the production of bricks" International Journal of Advance Research, Ideas and Innovations in Technology, vol. 4, Dec. 2018, pp. 2562-2569.

5. L. Zhang, "Production of bricks from waste materials - a review" Construction and Building Materials., vol. 47, Feb. 2013, pp. 643-655.

6. More, A. Tarade, A. Anant, “Assessment of suitability of Fly Ash and Rice Husk Ash burnt clay bricks” International Journal of Scientific Research Publications, vol. 4, Mar. 2014, pp. 1-6.
7. D. Tonnayopas, P. Tekasakul, S. Jaritgnam, "Effects of rice husk ash on characteristics of lightweight clay brick" International Conference on Technology and Innovation for Sustainable Development, Thailand, 2008.

8. K. Faria, R. Gurgel, J. Holanda, "Recycling of sugarcane bagasse ash waste in the Production of clay bricks" Journal of Environmental Management, vol. 101, Dec. 2012, pp. 7-12.

9. Saravanan J, Sridhar M, "Construction technology, challenges and possibility of low carbon buildings in India" International Journal of Civil Engineering, vol. 11, Dec. 2015, pp. 2678-2685.

10. Gunasekaran K, Kumar P S and Lakshmipathy M, "Mechanical and bond properties of coconut shell concrete" Construction and Building Materials, vol. 25, Sep. 2011, pp. 92-98.

11. Tiza Michael Toryila, Akuto Tersoo, Femi Agbede and Ugama Terry Ukande, "Production of Concrete Roofing tiles using Rice Husk Ash (RHA) in partial replacement of cement" International Research Journal of Engineering and Technology, vol. 3, Aug. 2016, pp. 2678-2685.

12. Bahurudeen A, Marckson A V, Arun Kishore and Manu Santhanam, "Development of Sugarcane Bagasse Ash based Portland Pozzolana cement and evaluation of compatibility with superplasticizers" Construction and Building Materials, vol. 68, July. 2014, pp. 465-475.

13. Maurice E. Ephraim, Godwin A. Akeke and Joseph O. Ukpata, "Compressive strength of concrete with rice husk ash as partial replacement of ordinary Portland cement" Scholarly Journal of Engineering Research, vol. 1, June 2012, pp. 32-36.

14. IS 1077 (1992) - Common Burnt Clay Building Bricks Specification.

15. IS 2690 (1992) - I - Specifications on burnt clay flat terracingtiles.

\section{AUTHORS PROFILE}

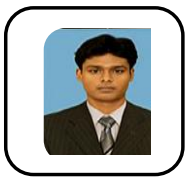

Jagan Sivamani completed M. Tech in Structura Engineering from VIT University in 2015, B.Tech in Civil Engineering from Kongu Engineering College in 2013. I am currently working as Assistant Professor at Kalasalingam Academy of Research and Education. During my career I have published my research worked in 8reputed International Journals and also attended many International conferences, workshops and seminars. Also, a life member of IAENG association. 